\title{
Separation of milk fat globules via microfiltration: Effect of diafiltration media and opportunities for stream valorization
}

\author{
A. Jukkola, ${ }^{* 1}$ R. Partanen, $†$ O. J. Rojas, ${ }^{*}$ and A. Heino† \\ *Bio-Based Colloids and Materials (BiCMat), School of Chemical Technology, Aalto University, PO Box 16300, 00076 Espoo, Finland \\ †Valio Ltd., R\&D Center, PO Box 30, 00039 Valio, Finland
}

\begin{abstract}
Milk fat globule membranes (MFGM) sourced in buttermilk have gained recent interest given their nutritional value and functional properties. However, production of isolated MFGM has been challenging given their size similarity with casein micelles, which limits attempts toward fractionation by size exclusion techniques. Therefore, the hypothesis underpinning this study is that the removal of proteins from cream before butter-making facilitates MFGM isolation. As such, milk fat globules were separated from raw whole milk via microfiltration $\left(1.4-\mu \mathrm{m}\right.$ pore diameter and $0.005 \mathrm{~m}^{2}$ filtration surface area) by using 3 diafiltration media; namely, skim milk ultrafiltration permeate, saline, and water. Their effects on the stability of the milk fat globules and protein permeation was elucidated. Whereas a substantial reduction in protein concentration was achieved with all diafiltration media ( $\sim 90 \%$ reduction), water and saline produced negligible membrane fouling with better filtration performance. Moreover, diafiltration with skim milk ultrafiltration permeate exhibited reduced permeate flux. Colloidal stability of the resultant milk decreased with all diafiltration solutions due to changing composition and reduced apparent viscosity. Overall, microfiltration was found to be an efficient method for separation of milk fat globules from whole milk, leading to increased MFGM fragment concentration in buttermilk dry matter, thus making it more suitable for industrial utilization.
\end{abstract}

Key words: diafiltration, microfiltration, milk fat globule membrane, milk fat separation

\section{INTRODUCTION}

Cream churning in butter processing disrupts the membrane of milk fat globules, and the resulting membrane fragments, known as a source of functional ingredients, are released into the aqueous phase, buttermilk.

Received May 9, 2016.

Accepted August 1, 2016.

${ }^{1}$ Corresponding author: annamari.jukkola@aalto.fi
Thus, recent attention surrounding buttermilk as a potential value-added ingredient in dairy products is not surprising (Corredig et al., 2003; Le et al., 2011; Phan et al., 2013, 2014). The advantageous nutritional and functional properties and the various isolation methods of milk fat globule membrane (MFGM) have been reviewed (Dewettinck et al., 2008; Holzmüller and Kulozik, 2016). Furthermore, many efforts have been applied to fractionate and concentrate MFGM fragments from buttermilk, for example, via filtration (Corredig et al., 2003; Rombaut et al., 2006; Fauquant et al., 2014). Such MFGM isolation is based on the selective removal of casein, whey proteins, lactose, and minerals, of which the similarity in size of casein micelles and MFGM fragments has been reported to be the major obstacle for fractionation (Dewettinck et al., 2008). Traditionally milk is separated into cream and skim milk by mechanical separation based on differences in colloidal particle velocity under a centrifugal field. Such separation leads to the enrichment of low-density particles, fat globules, into cream, but it is not selective to proteins. From cream, proteins enter into the butter-making process and eventually end up in buttermilk. Unlike centrifugal separation, membrane filtration is a pressure-driven process that fractionates colloidal particles from the suspension by size exclusion. Membrane filtration enables protein separation from cream before buttermaking for more efficient raw material usage. Hence, if most proteins are transferred to the skim milk, MFGM fragments can be fully exploited from buttermilk with minimal protein interference.

Milk is a complex system that can be fractionated, for example by cross-flow microfiltration (MF) with diafiltration (DF), which critically affects its physicochemical characteristics, such as a colloid diameter, electrostatic charge, hydration, mineral and protein composition, and so on (Jimenez-Lopez et al., 2011). The properties of milk play important roles not only in terms of milk functionality, but also in the effectiveness of related filtration processes. It is important to understand the interactions between milk components to control milk integrity and filtration performance. As a complex layer of surface material, MFGM naturally 
emulsifies the fat globules in milk. The structure of MFGM has been extensively studied and reported to consist of a phospholipid trilayer and a complex mixture of proteins and cholesterol (Fong et al., 2007; Gallier et al., 2012; Zou et al., 2015). The outer layer of the MFGM consists mainly of protruding glycocalyx and peripheral proteins (Singh, 2006), along with related structures that are considered native milk fat globules. Processing of the fat globules can lead to their coalescence and loss of membrane material, which enables the incorporation of proteins to resurface the fat globules and thus alters their physical properties. Washing cream can also selectively remove MFGM components from the interface and create accessible surfaces for casein and whey protein attachment (Kathriarachchi et al., 2014). In milk, caseins are present in the form of colloidal particles, the casein micelles, which contain some inorganic matter, mainly calcium phosphate (Walstra et al., 2006). Caseins tend to associate due to hydrophobic effects and have a fairly high charge caused by the phosphate groups, which strongly binds divalent ions such as $\mathrm{Ca}^{2+}$. Casein micelles undergo ion exchange with free ions; for example, addition of $\mathrm{NaCl}$ induces the displacement of casein-bound protons (Huppertz and Fox, 2006). Dynamic equilibrium of the casein micelle is primarily dependent on concentration, temperature, $\mathrm{pH}$, and ionic strength (as well as other physicochemical conditions). To enhance filtration performance, DF is commonly used in dairy processing, which mainly involves washing out permeating compounds with DF medium. Use of DF alters the ionic environment surrounding the casein micelles and, by disruption of the micelles, lead to losses of colloidal calcium phosphate and casein proteins into the serum phase (Ferrer et al., 2014). The reduction of $\mathrm{pH}$, or the addition of citrate or salt to milk, decreases the net surface charge of casein micelles and induces partial dissolution of the colloidal calcium that favors micelle disintegration (Jimenez-Lopez et al., 2011).

Milk membrane filtration systems are being exploited by the dairy industry for fractionation of milk proteins and removal of microorganisms (i.e., cold pasteurization; Beolchini, 2005; Hoffmann et al., 2006; Hurt and Barbano, 2010; Piry et al., 2012; Adams and Barbano, 2013). Skim milk is often used for milk membrane filtration processes, and filtration of fat-containing dairy fluids is mainly limited to defatting of whey (Golbandi et al. 2013). However, membrane filtration has been applied to separation of milk fat populations into small and large globules by MF (Goudedranche et al., 2000; Michalski et al., 2006) and for separation of anhydrous milk fat into fractions with different melting points (Abbas et al., 2006). Microfiltration of milk fat-rich dairy fluids is limited at the industrial scale, as milk fat has a role in membrane fouling. Fouling is a major challenge in all applications related to membrane filtration of milk. Fouling and concentration polarization are related to the deposition of a layer on the membrane surface and to the narrowing of the pores, which negatively affect the selectivity and filtration performance by flux reduction (Guerra et al., 1997; Fouladitajar et al., 2015). Concentration polarization, the formation of a dense, multicomponent layer at the walls of the filtration membrane, has remained one of the most important problems in pressure-driven membrane processes (Tashvigh et al., 2015). One way to prevent particle deposition and minimize fouling is to facilitate relatively higher shear at the membrane-liquid interface, which can be accomplished by use of high cross-flow velocities (4-8 m/s; Guerra et al., 1997). In addition to shear stress, MF performance can be controlled by the transmembrane pressure (TMP) and permeate flux (Gésan-Guiziou et al., 1999). High feed concentration and pressure leads to the formation of a thicker concentration polarization layer on the membrane wall (Fouladitajar et al., 2015). The formation of such a fouling layer can be inhibited by lowering the pressure and feed concentration and, in the case of whole milk MF, by reducing feed viscosity (e.g., by operating at temperatures above $50^{\circ} \mathrm{C}$ ).

The MF of fat-containing dairy fluids can enable the separation of specific milk fat components, including MFGM fragments. Because of interactions between MFGM components during their isolation and the size similarity with casein micelles, the full potential of MFGM remains an untapped opportunity. Morin et al. (2007) investigated the possibility of removing caseins from cream by centrifugal separation before buttermaking. It was found that by washing cream with skim milk ultrafiltration permeate the protein content in the cream decreased by $60 \%$, resulting in more effective MFGM fragment concentration from buttermilk. However, washing cream has been reported to release MFGM material and increase fat globule coalescence (Holzmüller et al., 2016). In addition, possible advantages of membrane separation over centrifugation include reduced energy consumption and less damage to shear-sensitive components, such as the MFGM (Brans et al., 2004). Furthermore, MF has not yet been considered for casein and milk fat separation. To the best of our knowledge, no reports exist on the application of MF toward native milk fat globule separation from milk or cream. Moreover, despite the extensive research devoted to the effect of minerals on the properties of milk proteins during filtration (Mao et al., 2012; Carpintero-Tepole et al., 2014; Ferrer et al., 2014), their 
effect on the physicochemical properties of whole milk during MF process has been ignored. Therefore, the main objective of our study was to investigate MF of raw whole milk for separation of milk fat from other components. Raw milk was chosen as raw material instead of cream to minimize effects other than those in MF processing. Water, skim milk ultrafiltration permeate (SMUF), and saline were used as DF media. This was in consideration of the fact that $\mathrm{DF}$ with water creates simple dilution conditions, SMUF retains the ion equilibrium of milk, and $\mathrm{NaCl}$ in saline shifts the ionic balance. Their effect on the stability of the milk fat globules and permeation of protein and DM was elucidated.

\section{MATERIALS AND METHODS}

\section{Materials}

Raw bovine milk was chosen as a feed $(1,500 \mathrm{~g})$ for filtration. The raw milk (fat $4.40 \pm 0.09 \%$, protein 3.49 $\pm 0.04 \%, \mathrm{DM} 13.36 \pm 0.12 \%, \mathrm{pH} 6.80 \pm 0.03)$ was collected from a dairy plant (Valio Ltd., Riihimäki, Finland) $1 \mathrm{~d}$ prior each experiment and stored at $5{ }^{\circ} \mathrm{C}$ before use. Millipore water (Merck, Kenilworth, NJ), SMUF, and $50 \mathrm{mM} \mathrm{NaCl}$ were used as diafiltration media. A relatively low saline concentration was chosen to avoid casein micelle concentration at the membrane surface (Jimenez-Lopez et al., 2011). The nonpasteurized SMUF was collected in one batch from a dairy plant (Valio Ltd., Äänekoski, Finland) and kept frozen $\left(-20^{\circ} \mathrm{C}\right)$ before processing. One day before each experiment, part of the SMUF was defrosted at $5^{\circ} \mathrm{C}$. Also, $50 \mathrm{mM} \mathrm{NaCl}$ (VWR Chemicals, Radnor, PA) aqueous solutions were prepared by using Millipore water $1 \mathrm{~d}$ before use. Approximately $1 \mathrm{~h}$ before the experiments, the raw milk and the diafiltration solution were heated to $50^{\circ} \mathrm{C}$ in a water bath. All reagents used were of analytical grade.

\section{MF}

MF System. Microfiltration was performed using a benchtop system (Sartoflow Study, Sartorius Stedim Biotech GmbH, Goettingen, Germany) equipped with single channel tubular ceramic membrane (Membralox T1-70, Pall Corporation, Port Washington, NY) with $1.4-\mu \mathrm{m}$ pore diameter and $0.005-\mathrm{m}^{2}$ filtration surface area (Figure 1). Process parameters (pressures, permeate flow, pump speed, weight, time) were controlled and monitored through Sartoflow DCU digital measurement and control system.

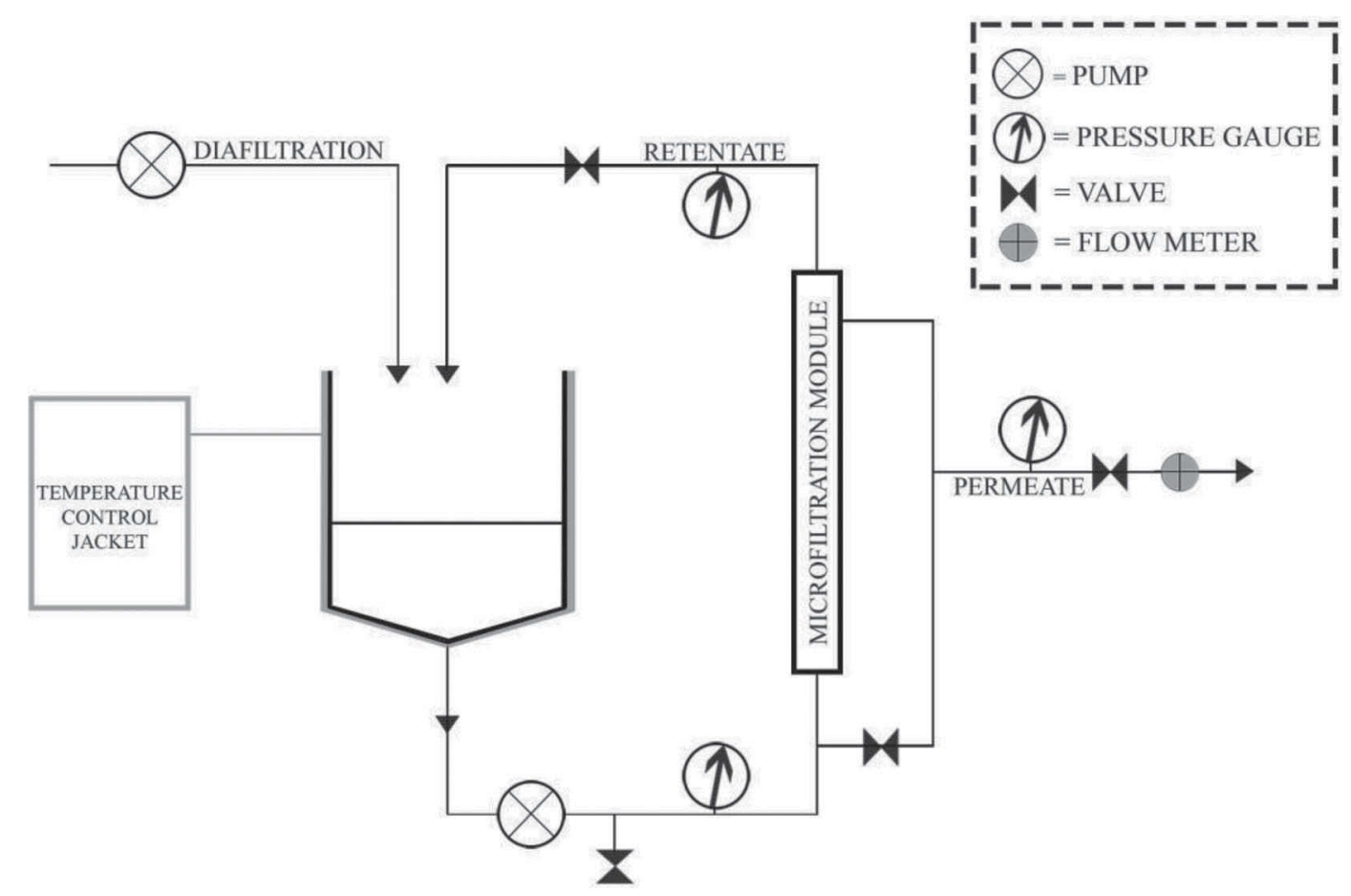

Figure 1. Microfiltration system (1.4- $\mu$ m ceramic membrane) used for milk fat separation. 
MF Cleaning. The day before processing, the filtration system was cleaned by performing a 3-step procedure. First, the temperature was slowly raised to $75^{\circ} \mathrm{C}$ and 10 to $20 \mathrm{~mL} / \mathrm{L}$ of $1.25 \mathrm{M} \mathrm{NaOH}$ solution was added to the retentate vessel. After $25 \mathrm{~min}$ of operation, the permeate valve was opened and circulated to the feed tank for a total washing time of $40 \mathrm{~min}$. After each cleaning step the system was flushed with water until neutral $\mathrm{pH}$. Second, a similar procedure as noted before was used for 15 min but using an acidic cleaning solution $\left(5-10 \mathrm{~mL} / \mathrm{L}\right.$ of $\left.1 \mathrm{M} \mathrm{HNO}_{3}\right)$ at $50^{\circ} \mathrm{C}$. The final cleaning step was similar to the first one, but using a more diluted $\mathrm{NaOH}$ solution of 5 to $10 \mathrm{~mL} / \mathrm{L}$ of 1.25 $M \mathrm{NaOH}$ with 25 min of cleaning time. The TMP was kept at $<100 \mathrm{kPa}$ during all steps. Pure water flux was measured with $50^{\circ} \mathrm{C}$ water after the cleaning procedure.

MF Trials. The system was heated to $50^{\circ} \mathrm{C}$ with hot water and temperature was kept constant by using a water bath jacket around the feed tank. The hot water was then displaced with a $50^{\circ} \mathrm{C} \mathrm{DF}$ solution by draining the water and adding $1 \mathrm{~kg}$ of DF solution to the feed tank. Then, with the permeate valve closed, all the retentate was collected and discarded. Another $1 \mathrm{~kg}$ of DF solution was added to the feed tank and, with the permeate valve open, the permeate was collected and discarded until the feed tank was emptied. The same DF solution was used for water displacement as for filtration procedures. To start the process, $1,550 \mathrm{~g}$ of $50^{\circ} \mathrm{C}$ raw milk was added to the feed tank and the pump speed was gradually increased to achieve a constant $5 \mathrm{~m} / \mathrm{s}$ cross-flow velocity along the membrane surface (measured previously). Retentate was circulated back to the feed tank and the permeate valve was carefully opened until TMP reached 10 to $20 \mathrm{kPa}$. Then, $200 \mathrm{~g}$ of permeate was collected and discarded before circulating permeate to the feed tank to eliminate excess DF solution. A 30-min start-up stabilization time was used before starting the MF and a 50-g sample was withdrawn from the feed so that the net amount of feed before MF was $1,500 \mathrm{~g}$. The diafiltration was automatically adjusted to keep the feed weight constant by pumping the $50^{\circ} \mathrm{C}$ DF solution to the feed using a peristaltic pump, this way the feed was kept at the same concentration. Then, the MF process was started by allowing permeate to exit the system for collection and further analyses. Permeate was collected in four 750-g batches to obtain 50, 100, 150, and 200\% DF levels of feed weight. At the same time, with each permeate sample, $8 \mathrm{~mL}$ of respective retentate was withdrawn from the feed tank to obtain 50,100, 150, and $200 \%$ DF level retentate samples. The filtration temperature was kept fairly constant, in the 50 to $55^{\circ} \mathrm{C}$ range. After processing, the system was rinsed with water and cleaned following the same washing procedure described previously. Samples for chemical composition analyses were stored at $-20^{\circ} \mathrm{C}$ whereas those for physical testing were cooled $\left(5^{\circ} \mathrm{C}\right)$ and analyzed within $24 \mathrm{~h}$.

\section{Calculations of Microfiltration Performance}

Permeation $(P r)$ of fat, protein, and DM was calculated as

$$
\operatorname{Pr} \%=\frac{m_{\text {per }}}{m_{\text {feed }}+m_{D F}} \times 100,
$$

where $m_{\text {per }}, m_{\text {feed }}$, and $m_{D F}$ are the masses $(\mathrm{kg})$ of the component in the permeate, feed and DF solution, respectively.

The mass flow $\left(\dot{m} ; \mathrm{kg} / \mathrm{h} / \mathrm{m}^{2}\right)$, for each component was calculated according to

$$
\dot{m}=\frac{\left(m_{\text {per }}-m_{\text {DFper }}\right) / t}{A},
$$

where $m_{\text {DFper }}$ is the mass $(\mathrm{kg})$ of the component from DF solution in permeate, $t$ is the filtration time (h), and $A$ is the membrane surface area $\left(\mathrm{m}^{2}\right)$. To estimate the true raw milk separation efficiency, $m_{D F p e r}$ was subtracted from the component mass in the permeate. As permeate was collected according to the different DF levels, the total $m_{D F p e r}$ is dependent on the permeation of each DF level:

$$
\begin{aligned}
& m_{D F p e r}=P r_{50 \%} \times m_{D F 50 \%}+P r_{100 \%} \times\left(m_{D F 100 \%}+m_{D F r e t 50 \%}\right)+ \\
& P r_{150 \%} \times\left(m_{D F 150 \%}+m_{D F r e t 100 \%}\right)+P r_{200 \%} \times\left(m_{D F 200 \%}+m_{D F r e t 150 \%}\right),
\end{aligned}
$$

where 50,100,150, and $200 \%$ indicates the DF steps and $m_{D F r e t}$ is the mass of the component from DF solution in the retentate.

\section{Analyses}

Composition. Dry matter analyses were performed by gravimetric difference after heating the samples to $105^{\circ} \mathrm{C}$ overnight (Le et al., 2011). Total lipid content was obtained gravimetrically using the Röse-Gottlieb extraction method (ISO-IDF, 2010). The protein content was obtained spectrophotometrically using the Bradford dye-binding method (Protein Assay, Bio-Rad Laboratories Inc., Hercules, CA) with standard protein curve of skim milk powder. 
Particle Sizing and Zeta Potential. The particle size distributions in the MF feed and retentates were determined by laser light scattering using a Mastersizer 2000 (Malvern Instruments, Malvern, UK) according to Ye et al. (2011). A refractive index of 1.458 was used for bovine milk fat. The measurements were performed with dilution in water. Three readings were collected from each individual sample and the measurements were run in triplicate.

The zeta potential of the milk fat globules were measured the day following sample collection by using a dynamic light scattering instrument (Zetazizer, Nano series ZS90, Malvern Instruments) according to Michalski et al. (2001). Samples were diluted 100 fold in water and measured in a Malvern Dip Cell at $20^{\circ} \mathrm{C}$. A 2-min equilibrium time was allowed before each measurement. Three readings were collected from each individual sample and the measurements were run in triplicate.

Creaming. Creaming measurements were performed after sample collection to detect differences in stability before and after MF. A scanning light scattering instrument (Turbiscan MA 2000, Formulaction, Toulouse, France) was used for this purpose according to Juliano et al. (2011). Six milliliters of feed and 200\% $\mathrm{DF}$ retentate from each filtration were pipetted into the Turbiscan measurement tube. Measurement scans were performed first in 30-min cycles for the first $3 \mathrm{~h}$ followed by acquisition after 17, 20, and $24 \mathrm{~h}$. Samples were stored at $8^{\circ} \mathrm{C}$ between measurements.

\section{Statistical Analysis}

One-way ANOVA was used to calculate significant differences (95.0\% confidence level) between the samples using Minitab 17 Statistical Software (Minitab Inc. State College, PA).

\section{RESULTS AND DISCUSSION}

\section{MF Efficiency}

Before permeate collection, the system was stabilized for $30 \mathrm{~min}$ by circulating permeate back to the feed tank. During this time the hydraulic resistances of the membrane were assumed to equilibrate before starting DF. The permeate fluxes for SMUF, saline, and water DF were found to differ at the very beginning of MF: $693 \pm 50,853 \pm 64$ and $823 \pm 49 \mathrm{l} / \mathrm{h} / \mathrm{m}^{2}$, respectively. The permeate flux obtained at the beginning of filtration remained at the same level with saline and water DF, whereas it decreased with time in the case of SMUF DF (Figure 2). The DF solutions were already affecting the permeate flux at the starting point of MF, where an excess of DF solution from the filtration unit pipelines was mixed with the feed during the start-up stabilization procedure. Even small amounts of DF solution altered the composition of the feed and related interactions, and therefore affected filtration performance. Dry matter content and viscosity of the feed was higher in SMUF DF compared with saline and water DF, both of which decreased milk viscosity and led to higher permeate flux. The SMUF DF brought more DM mass in the retentate compared with saline and water DF, and therefore the permeate flux of SMUF DF decreased due to increased resistance. Diafiltration with saline and water decreased retentate DM content significantly during the MF process, offsetting the otherwise expected reduction in permeate flux during filtration. The dilute saline (50 $\mathrm{m} M \mathrm{NaCl}$ solution) did not decrease the flux during raw milk MF, which is in contrast to findings of Jimenez-Lopez et al. (2011) and Carpintero-Tepole et al. (2014), who indicated a decreased flux when high concentrations of salts or minerals were present during skim milk filtration. This was ascribed to the dissociation of casein micelles, which increases retentate viscosity. Increased resistance of the membrane in our study was also observed with an increase in TMP with SMUF DF (Figure 2). In contrast, TMP decreased with saline and water DF, which is explained by the reduction in DM content. An associated effect was total processing time, in which average processing times of $200 \%$ DF for SMUF, saline, and water DF were 64,41 , and 45 min, respectively. The values for SMUF DF differed significantly from the saline and water DF, indicating that the process was clearly being hindered by SMUF DF, with increased resistance due to concentration polarization and fouling. We noted that filtration time in our experiments was relatively short, hence long-term fouling effects were not assessed.

The differences in filtration behavior can be explained by a change in ionic equilibrium. The $\mathrm{pH}$ of the retentate after water and saline DF was $7.34 \pm$ 0.04 and $7.28 \pm 0.05$, respectively, whereas the $\mathrm{pH}$ after SMUF DF was $6.67 \pm 0.01$; thus, the comparative ionic strength of milk was reduced with water and saline DF. As a consequence, it was expected that the casein proteins were subjected to increased repulsive electrostatic and hydrophilic interactions (Liu and Guo, 2008; Carpintero-Tepole et al., 2014). The role of electrostatic interactions involving casein micelles on permeate flux has been reported by several authors (Rabiller-Baudry et al., 2005; Bouzid et al., 2008; Ferrer et al., 2014). Increased electrostatic repulsion most likely limited packing of the concentration polarization layer and inhibited the formation and deposition of a fouling layer on the filtration membrane, resulting in enhanced filtration performance. 

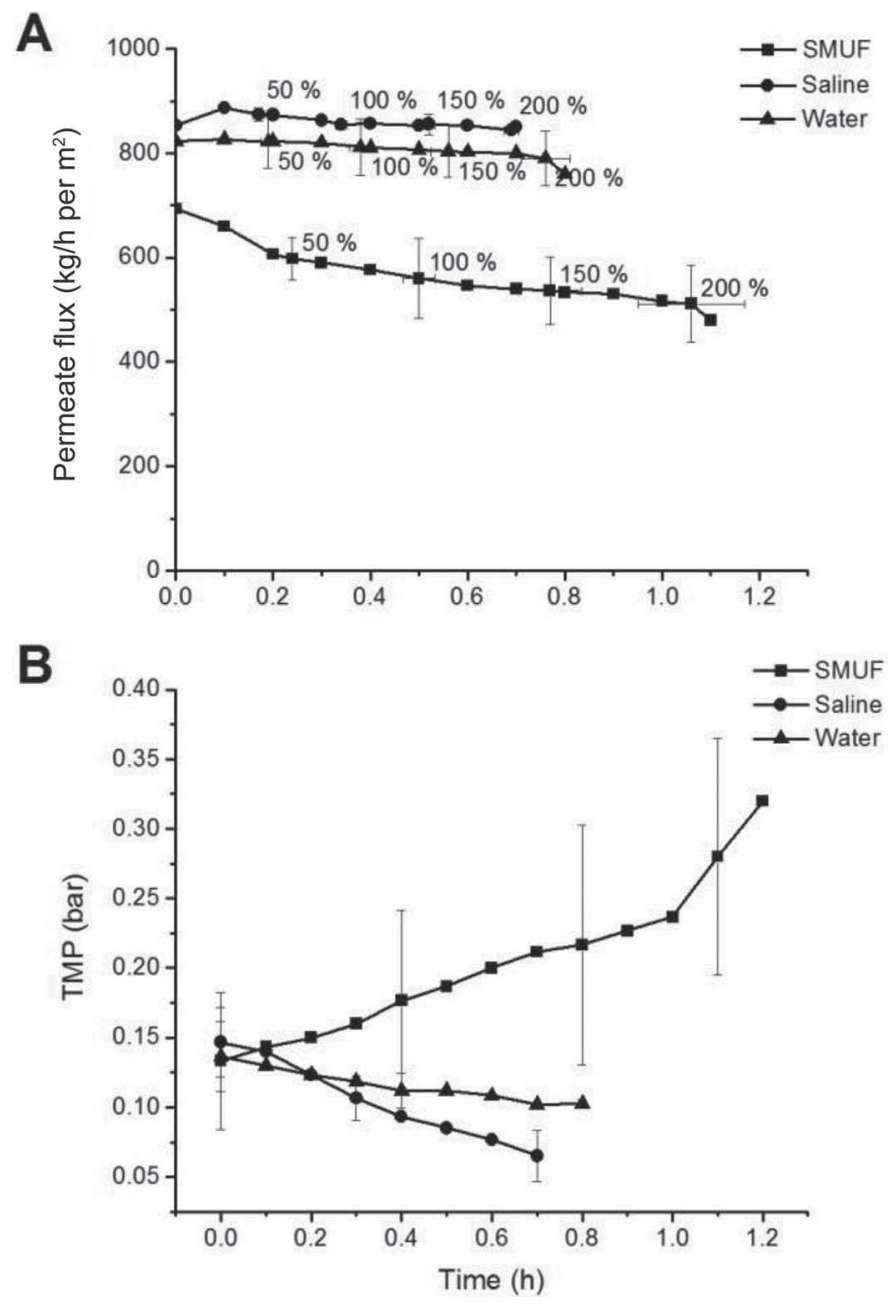

Figure 2. Permeate flux (A) and transmembrane pressure (TMP; B) as a function of time during micro-diafiltration of raw milk with skim milk ultrafiltration permeate (SMUF), saline $(50 \mathrm{mM} \mathrm{NaCl})$, and water. The average of 3 experiments is presented and bars represent SD. Percentages are relative to the amount of diafiltration.

\section{Chemical Composition of Retentate and Permeate}

Fat content of the retentates slightly decreased during filtration due to permeation of small fat globules into the permeate (Figure 3). It is well known that milk fat globules have wide particle size distribution, in the range of approximately 0.2 to $15 \mu \mathrm{m}$ (Huppertz and Kelly, 2006); thus, small fat globule fractions likely permeated through the 1.4- $\mu \mathrm{m}$ membrane pores. The calculated fat permeation was_approximately $2.5 \%$ in each experiment, with no significant differences observed for the different DF media (Table 1). The protein content of the retentates decreased continuously during filtration, resulting in rather similar protein concentrations at the end of each filtration. No significant differences in protein permeations were found, approximately $88 \%$ in all DF, suggesting that the larger fouling deposits in SMUF DF was not selective for protein. The DM in SMUF DF retentate was consistently higher as compared with saline and water DF retentates, which was due to the higher DM content in the SMUF DF medium (Figure 3). Nevertheless, after subtracting the DM content of SMUF using equation [1], the difference in DM permeation was evened out. To estimate total separation efficiency in the MF process, the mass flow for each component was calculated (Table 1). The component separation from raw milk was accounted more properly if all component mass coming from DF were subtracted from equation [2]. According to calculations comparing to water and saline DF, protein separation from raw milk was slower in SMUF DF because of its lower permeate flux and longer processing time. Lower separation efficiency using SMUF DF was also observed in the mass flows of fat and DM.

Our results for protein permeation are comparable with Morin et al. (2007), who reported a $60 \%$ decrease in protein content for cream when washed with SMUF and separated by centrifugation. Overall, MF can be considered as a suitable and effective step for protein removal, enabling MFGM component concentration from buttermilk if the cream is MF before butter making.

\section{Effect of Diafiltration on the Physicochemical Properties of Milk Fat Globules}

Particle Size. The results of filtration experiments indicate no or negligible changes in the size of milk fat globules in the retentate (Figure 4). This is in agreement with previous reports indicating that MF does not cause homogenization of milk (Glimenius et al., 1979). In contrast, the volume-weighted size mean for milk fat globules in the retentate slightly increased during MF (always being the highest in the 200\% DF samples; Table 2). Kathriarachchi et al. (2014) reported an increase in milk fat globule size when washing cream with SMUF or deionized water, which was explained by coalescence during centrifugation. However, we suggest that the increased particle size characteristic after MF is most likely caused by permeation of the smallest fat globules through the 1.4- $\mu \mathrm{m}$ membrane. We note, in passing, that a peak in the distribution below $1 \mu \mathrm{m}$ was observed in each measurement, which was taken as an artifact as also indicated by Michalski et al. (2001). This may be caused by overestimated light absorption index, but did not influence particle size distribution above $1 \mu \mathrm{m}$. In summary, the absence of small milk fat globules and, possibly, permeation of casein micelles (which cause low diffraction intensities, not enough to 
Table 1. Effect of diafiltration on permeation and mass flow of fat, protein, and DM in raw whole milk microfiltration ${ }^{1}$

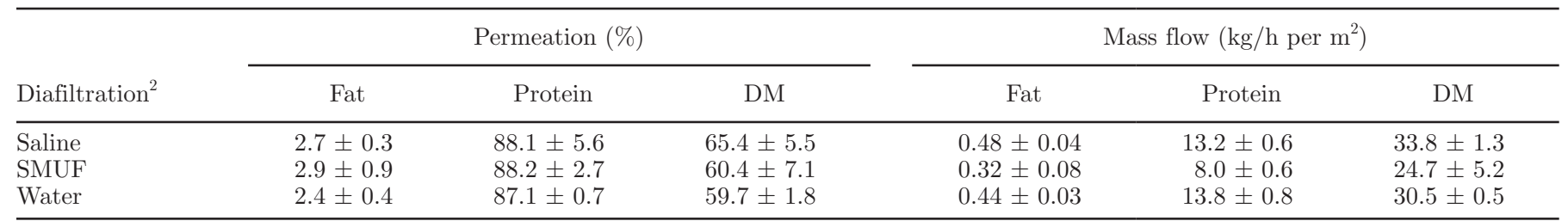

${ }^{1}$ Means \pm SD of 3 replicates.

${ }^{2}$ Diafiltration media: saline $=50 \mathrm{mM} \mathrm{NaCl}$; SMUF $=$ skim milk UF permeate.

be resolved from the data) increased the mean particle size, but caused no major differences in particle size distribution.

Zeta Potential. Zeta potential values for the feed milk were close to $-30 \mathrm{mV}$, which indicates good colloidal stability (Schramm, 2014). The negative potential values increased with $\mathrm{DF}$ in all cases (Table 2). At the end of DF (200\%), the lower pH of the SMUF retentate did not affect zeta potential, which settled in between the values of water and saline retentates. Most likely, the $\mathrm{pH}$ difference was leveled out by the high dilution coefficient (1:100 in water). The zeta potential of milk fat globules in retentate was already relatively low at the beginning of MF compared with the zeta potential of milk fat globules, from -13.5 to $-38 \mathrm{mV}$, as reported previously (Michalski et al., 2002; Ye et al.,

\section{Permeate}

\section{Retentate}
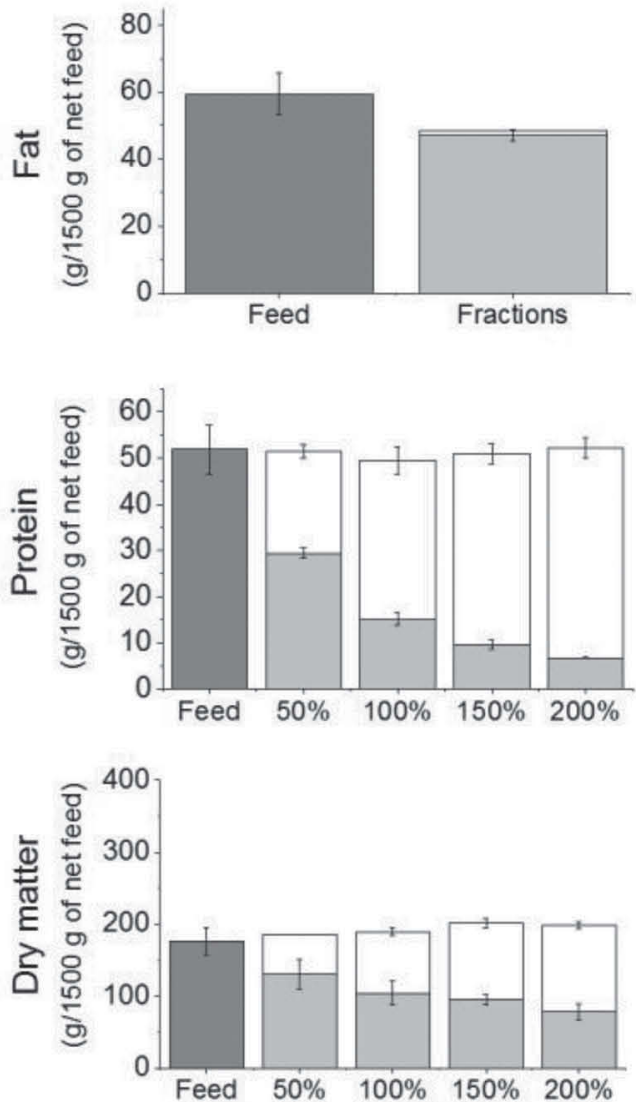
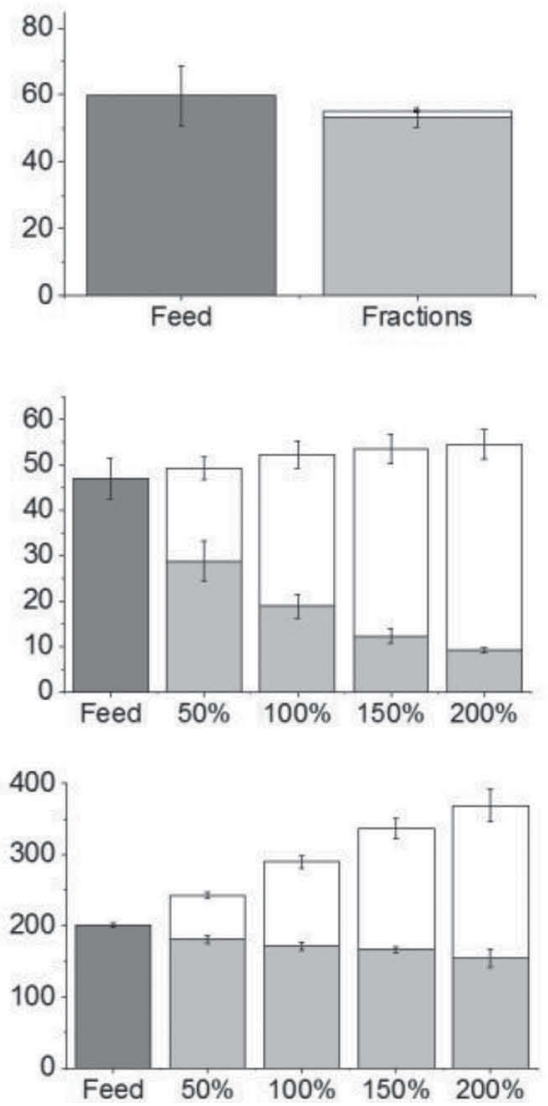

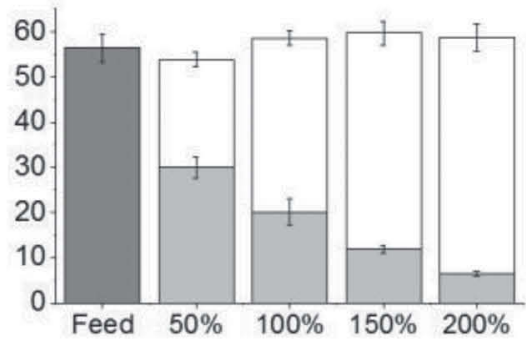

Water DF

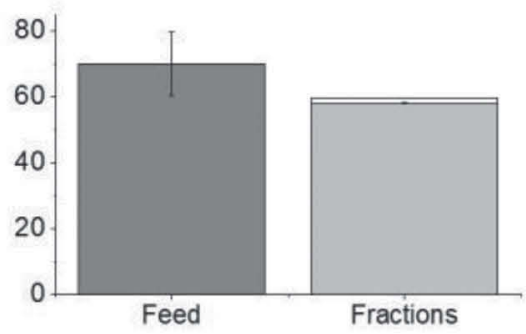

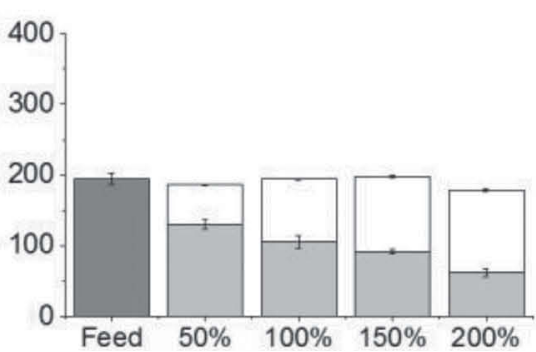

Figure 3. Mass balance of fat, protein, and DM in raw milk feed before microfiltration and in resulting retentate and permeate after different level $(\%)$ of diafiltration (DF) with saline $(50 \mathrm{mM} \mathrm{NaCl})$, skim milk ultrafiltration permeate (SMUF), and water. The average of 3 experiments is presented and bars represent SD. 


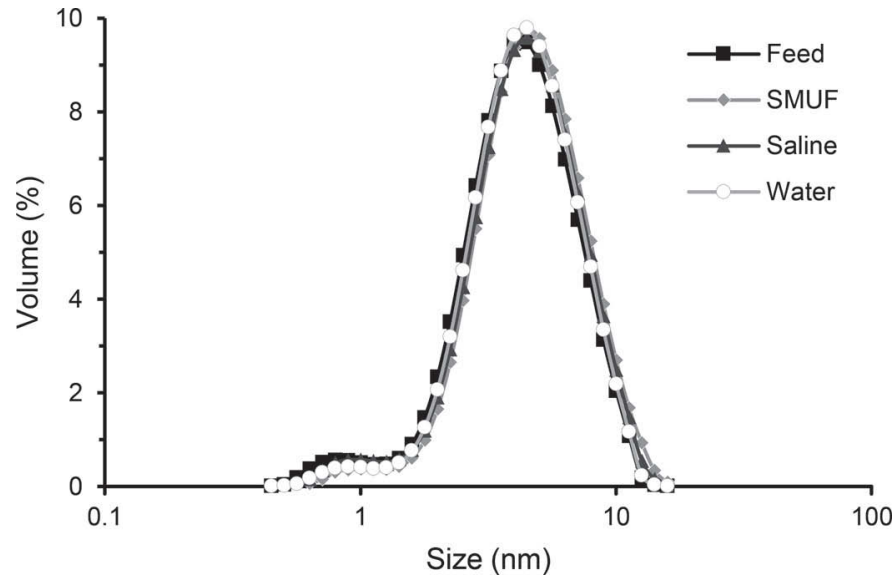

Figure 4. Particle size distribution of raw milk before (feed) and after (retentate) micro-diafiltration with skim milk ultrafiltration permeate (SMUF), saline $(50 \mathrm{mM} \mathrm{NaCl})$, and water. The average of 3 experiments is presented for each diafiltration media.

2011; Sharma et al., 2015). The increase in negative zeta potential might be caused by a damaged MFGM surface or by incorporation of skim milk proteins to the MFGM surface. Caseins have zeta potential of -20 $\mathrm{mV}$ (Michalski et al., 2002; Rabiller-Baudry et al., 2005), and incorporation of caseins to the surface of milk fat globules would therefore alter their charge. In our experiment, the fat globules in the feed samples were already subjected to shear stress, and one cannot rule out the possible incorporation of air during the start-up stabilization before MF and possible changes to the interfacial layer. Several authors have reported similar effects of a damaged MFGM surface in washed milk fat globules during centrifugation (Michalski et al., 2002; Le et al., 2009; Kathriarachchi et al., 2014). In addition, washing milk or cream can remove loosely attached membrane proteins such as mucin 1, periodic acid Schiff 6/7, and proteose peptone 3. Moreover, increased washing has been reported to increase the amount of proteose peptone 3, suggested to result from proteolytic breakdown of the MFGM proteins (Le et al., 2009). The type of protein attached to a disrupted
MFGM surface or released from the surface depends on the type of DF or washing solution used. In our experiments, increased DF resulted in an increased negative zeta potential for all DF solutions. However, the increase in negative zeta potential was more substantial with saline DF, followed by SMUF and water DF (Table 2).

The salts in the DF solution altered the ionic balance in milk and affected the electrostatic repulsions between fat globules by decreasing the thickness of the electrostatic double layer (Debye length). Of the DF solutions used, SMUF contains approximately $6.75 \mathrm{~g} / \mathrm{L}$ milk salt concentration (Le et al., 2009), thus retaining the normal equilibrium in milk; therefore, the increased negative zeta potential was mainly influenced by protein permeation and possible changes to the MFGM surface. With a salt concentration of $2.92 \mathrm{~g} / \mathrm{L}, \mathrm{NaCl}$ caused only a limited decrease in the thickness of the electrostatic double layer. In addition, saline DF increased the milk $\mathrm{pH}$ by promoting calcium binding to chloride and by increasing the amount of soluble phosphate, thus altering the ionic balance and lowering zeta potential. The zeta potential was measured the day after sample collection, which provided time for dissolution of calcium phosphates and formation of a new equilibrium. In contrast, water DF did not decrease the electrical double layer, as no counter-ions were involved. Furthermore, the dissolution of colloidal phosphates was slower compared with that with saline DF, as cations in milk permeated with anions during water DF due to membrane potential. Nevertheless, colloidal phosphates dissolved during the equilibrium formation. Therefore, the observed increase in negative zeta potential with water DF was mainly the result of an increased concentration of soluble phosphate.

Our measured zeta potentials for milk fat globules were relatively low and much more negative than those for caseins. Heating milk to $55^{\circ} \mathrm{C}$ has been shown to decrease the zeta potential due to damaged MFGM and adsorption of proteins (Sharma et al., 2015), which suggests that this might be a factor in our study as well.

Table 2. Zeta potential and mean particle size of feed and retentate as a function of diafiltration (DF) level and media in raw whole milk microfiltration $^{1}$

Particle size

Zeta potential $(\mathrm{mV})$

Volume-weighted mean $(\mu \mathrm{m})$

\begin{tabular}{|c|c|c|c|c|c|c|}
\hline \multirow[b]{2}{*}{ Sample } & & \\
\hline & Saline & SMUF & Water & Saline & SMUF & Water \\
\hline Retentate $50 \% \mathrm{DF}$ & $-31.4 \pm 2.6$ & $-31.3 \pm 2.2$ & $-30.3 \pm 1.7$ & $4.32 \pm 0.14$ & $4.58 \pm 0.17$ & $4.40 \pm 0.09$ \\
\hline Retentate $200 \%$ DF & $-36.4 \pm 2.8$ & $-33.9 \pm 1.4$ & $-31.5 \pm 1.9$ & $4.60 \pm 0.33$ & $4.80 \pm 0.08$ & $4.65 \pm 0.08$ \\
\hline
\end{tabular}

${ }^{1}$ Diafiltration media: saline $=50 \mathrm{~m} M \mathrm{NaCl}$; SMUF $=$ skim milk UF permeate; means \pm SD of 3 replicates. 
In addition, the MF process and storage time before MF could have contributed to the release of MFGM proteins to the serum phase, which might have affected the surface charge of the globules. Furthermore, the equilibration time before measurements allowed dissolution of colloidal phosphate, thus increasing the $\mathrm{pH}$ of the milk. A more detailed understanding of the surface properties of MFGM remains a subject for further studies.

Stability. Stability measurements were carried out to detect differences in the stability of milk before and after MF. Creaming of the samples, detected by increased backscattering on the upper layer formed in the Turbiscan tube, was significantly promoted by the MF process, causing retentate samples to form cream layers faster compared with that of the feed samples (Figure $5)$. The difference was found to be already significant after $30 \mathrm{~min}$ and during the first $3 \mathrm{~h}$ of measurement. The difference was no longer significant after $17 \mathrm{~h}$. The samples were subjected to similar creaming rates except that the retentates creamed faster. No significant differences were found between the different DF samples. Overall, it can be concluded that the absence of proteins caused an increase in colloidal instability in the retentate samples. Indeed, the absence of almost all protein probably lowered the continuous phase viscosity, which, according to Stoke's law, is a factor affecting creaming (Kessler, 2002). The effect of proteins on stability due to altered viscosity has been previously suggested (Sajedi et al., 2014).

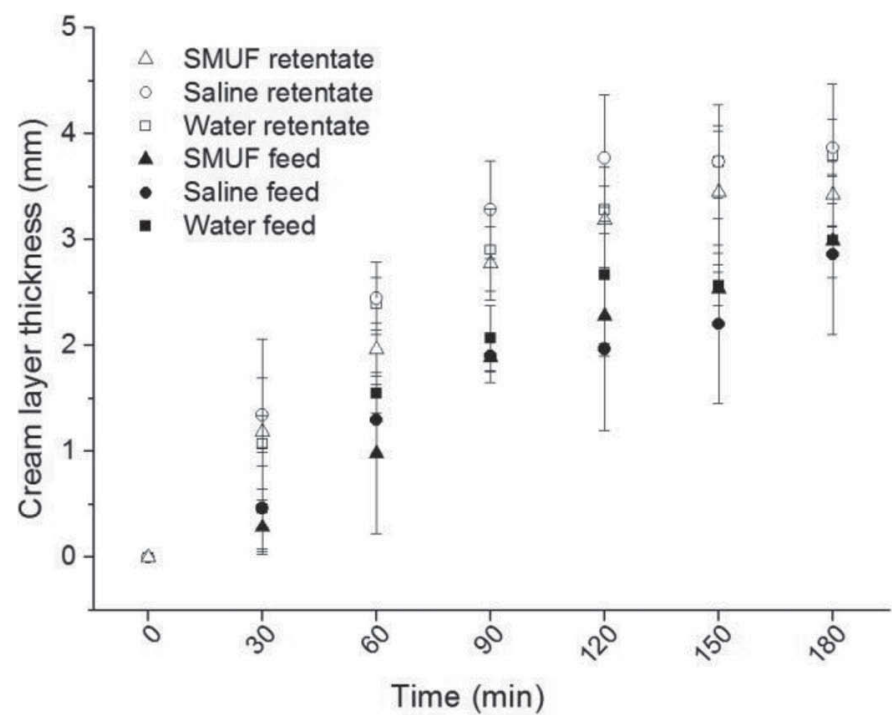

Figure 5. Formation of a cream layer as measured by back-scattered light during $24 \mathrm{~h}$ before (feed) and after (retentate) raw milk micro-diafiltration with saline $(50 \mathrm{mM} \mathrm{NaCl})$, skim milk ultrafiltration permeate (SMUF), and water. The average of 3 experiments is presented and bars represent SD.
The reduction in the thickness of the electrostatic double layer by the presence of ions can also result in a low stability, coalescence, and eventual loss of MFGM material. An increased probability of milk fat globule coalescence by decreased electrostatic double layer was reported by Holzmüller et al. (2016), who used a centrifugal separator for washing cream. Compared with water, SMUF washing reduced the electrostatic double layer (affecting repulsive forces) in milk fat globules. Thus, SMUF favors coalescence, mechanical damage, and increased particle size of fat globules (Holzmüller et al., 2016). In the present study, some visible butter grains were formed in the retentate of $200 \%$ DF samples $1 \mathrm{~d}$ after processing (during sample preparation for analysis), which suggests coalescence of fat globules. Whereas the possibility of MFGM damage during MF cannot be ruled out as a reason for butter grain formation, it is likely that this effect derived from incorporation of air, shear-induced coalescence during sample preparation, crystallization of fat globules during cold storage, and bridging of the crystallized globules during creaming. It can be speculated that in the absence of protein the stability is lower and the whipping time shorter (less competition for the interface, less protein to stabilize air), which favors butter grain formation.

Deionized water has been reported to be the best washing solution for milk fat globules, resulting in a high yield of MFGM proteins and low skim milk protein concentration (Le et al., 2009; Kathriarachchi et al., 2014). Compared with SMUF and saline DF, no enhanced stability against creaming was observed with water DF. Thus, it is plausible that the observed stabilization effect via electrostatic repulsion was offset by the lower viscosity of the medium and, therefore, within the experimental deviation, no differences between the different DF fluids was noticed.

\section{CONCLUSIONS}

In this study, we achieved a remarkable reduction in protein content $(88 \%)$ and retention of fat in whole milk $(97 \%)$ by $\mathrm{MF}$ with a $1.4-\mu \mathrm{m}$ ceramic membrane. The filtration performance of raw whole milk for separation of milk fat globules was influenced by the DF medium, whereas, in comparison to SMUF, permeate flux and mass flow were higher for DF with saline or water. With SMUF DF media, the DM composition of the milk remained nearly constant and a significant decrease in permeate flux and increase in TMP were observed during filtration. This is ascribed to an increased fouling resistance across the membrane. In addition, the electrostatic repulsion between casein micelles and fat globules was increased by the higher $\mathrm{pH}$ of saline and water DF, which improved filtration performance. The 
reduction in viscosity of the retentate also lowered the stability of the emulsions, leading to faster creaming of the milk, thus leading to possible modifications in the subsequent butter-making process. This, together with a detailed account of the changes in the structure of MFGM, are issues that are being addressed and will be reported in the future.

\section{ACKNOWLEDGMENTS}

The authors acknowledge Valio Ltd. for funding this project and providing raw materials. In addition, the authors thank Tero Eerikäinen (Aalto University, Espoo, Finland) and Klaus Muuronen (Valio Ltd., Helsinki, Finland) for their technical help and advice with the microfiltration. We are grateful to Marjatta Vahvaselkä and Mika Sipponen (Aalto University) for their technical laboratory analytical support. Kalle Simanainen (Valio Ltd., Riihimäki, Finland) is acknowledged for his help in providing the milk samples.

\section{REFERENCES}

Abbas, H., M. M. Hossain, and X. D. Chen. 2006. A laboratory investigation of the anhydrous milkfat fractionation using a membrane technique. Separ. Purif. Tech. 48:167-175.

Adams, M. C., and D. M. Barbano. 2013. Serum protein removal from skim milk with a 3 -stage, $3 \times$ ceramic isoflux membrane process at $50^{\circ}$ C. J. Dairy Sci. 96:2020-2034.

Beolchini, F. 2005. Microfiltration of bovine and ovine milk for the reduction of microbial content: Effect of some operating conditions on permeate flux and microbial reduction. Sep. Sci. Technol. 40:757-772.

Bouzid, H., M. Rabiller-Baudry, L. Paugam, F. Rousseau, Z. Derriche, and N. E. Bettahar. 2008. Impact of zeta potential and size of caseins as precursors of fouling deposit on limiting and critical fluxes in spiral ultrafiltration of modified skim milks. J. Membr. Sci. 314:67-75.

Brans, G., C. G. P. H. Schroën, R. G. M. van der Sman, and R. M. Boom. 2004. Membrane fractionation of milk: State of the art and challenges. J. Membr. Sci. 243:263-272.

Carpintero-Tepole, V., E. Brito-de la Fuente, E. Martínez-González, and B. Torrestiana-Sánchez. 2014. Microfiltration of concentrated milk protein dispersions: The role of $\mathrm{pH}$ and minerals on the performance of silicon nitride microsieves. LWT Food Sci. Technol. 59:827-833.

Corredig, M., R. R. Roesch, and D. G. Dalgleish. 2003. Production of a novel ingredient from buttermilk. J. Dairy Sci. 86:2744-2750.

Dewettinck, K., R. Rombaut, N. Thienpont, T. T. Le, K. Messens, and J. Van Camp. 2008. Nutritional and technological aspects of milk fat globule membrane material. Int. Dairy J. 18:436-457.

Fauquant, J., E. Beaucher, C. Sinet, B. Robert, and C. Lopez. 2014. Combination of homogenization and cross-flow microfiltration to remove microorganisms from industrial buttermilks with an efficient permeation of proteins and lipids. Innov. Food Sci. Emerg. Technol. 21:131-141.

Ferrer, M., M. Alexander, and M. Corredig. 2014. Changes in the physico-chemical properties of casein micelles during ultrafiltration combined with diafiltration. LWT Food Sci. Technol. (Campinas.) $59: 173-180$.

Fong, B. Y., C. S. Norris, and A. K. H. MacGibbon. 2007. Protein and lipid composition of bovine milk-fat-globule membrane. Int. Dairy J. 17:275-288.
Fouladitajar, A., F. Z. Ashtiani, B. Dabir, H. Rezaei, and B. Valizadeh. 2015. Response surface methodology for the modeling and optimization of oil-in-water emulsion separation using gas sparging assisted microfiltration. Environ. Sci. Pollut. Res. Int. 22:2311-2327.

Gallier, S., K. C. Gordon, and H. Singh. 2012. Chemical and structural characterisation of almond oil bodies and bovine milk fat globules. Food Chem. 132:1996-2006.

Gésan-Guiziou, G., E. Boyaval, and G. Daufin. 1999. Critical stability conditions in crossflow microfiltration of skimmed milk: Transition to irreversible deposition. J. Membr. Sci. 158:211-222.

Glimenius, A. R., G. T. Jansson, K. W. H. Kemi, and R. M. Sandblom, inventors. 1979. Filtering method for separating skim milk from milk products. Alfa-Laval Ab., assignee. US Pat. No. 4140806 A.

Golbandi, R., M. A. Abdi, A. A. Babaluo, A. B. Khoshfetrat, and T. Mohammadlou. 2013. Fouling study of TiO2-boehmite MF membrane in defatting of whey solution: Feed concentration and $\mathrm{pH}$ effects. J. Membr. Sci. 448:135-142.

Goudedranche, H., J. Fauquant, and J. Maubois. 2000. Fractionation of globular milk fat by membrane microfiltration. Lait 80:93-98.

Guerra, A., G. Jonsson, A. Rasmussen, E. Waagner Nielsen, and D. Edelsten. 1997. Low cross-flow velocity microfiltration of skim milk for removal of bacterial spores. Int. Dairy J. 7:849-861.

Hoffmann, W., C. Kiesner, I. Clawin-Rädecker, D. Martin, K. Einhoff, P. C. Loranzen, H. Meisel, P. Hammer, G. Suhren, and P. Teufel. 2006. Processing of extended shelf life milk using microfiltration. Int. J. Dairy Technol. 59:229-235.

Holzmüller, W., and U. Kulozik. 2016. Technical difficulties and future challenges in isolating membrane material from milk fat globules in industrial settings - A critical review. Int. Dairy J. 61:51-66.

Holzmüller, W., M. Müller, D. Himbert, and U. Kulozik. 2016. Impact of cream washing on fat globules and milk fat globule membrane proteins. Int. Dairy J. 59:52-61.

Huppertz, T., and P. F. Fox. 2006. Effect of $\mathrm{NaCl}$ on some physicochemical properties of concentrated bovine milk. Int. Dairy J. $16: 1142-1148$.

Huppertz, T., and A. L. Kelly. 2006. Physical chemistry of milk fat globules. Pages 173-212 in Advanced Dairy Chemistry. Vol 2: Lipids. P. F. Fox and P. L. H. McSweeney, ed. Springer, New York, NY.

Hurt, E., and D. M. Barbano. 2010. Processing factors that influence casein and serum protein separation by microfiltration. J. Dairy Sci. 93:4928-4941.

ISO-IDF. 2010. Milk-Determination of fat content. International Standard ISO 1211 and IDF 1:2010. ISO, Geneva, Switzerland and IDF, Brussels, Belgium.

Jimenez-Lopez, A. J. E., N. Leconte, F. Garnier-Lambrouin, A. Bouchoux, F. Rousseau, and G. Gésan-Guiziou. 2011. Ionic strength dependence of skimmed milk microfiltration: Relations between filtration performance, deposit layer characteristics and colloidal properties of casein micelles. J. Membr. Sci. 369:404-413.

Juliano, P., A. Kutter, L. J. Cheng, P. Swiergon, R. Mawson, and M. A. Augustin. 2011. Enhanced creaming of milk fat globules in milk emulsions by the application of ultrasound and detection by means of optical methods. Ultrason. Sonochem. 18:963-973.

Kathriarachchi, K., M. Leus, and D. W. Everett. 2014. Oxidation of aldehydes by xanthine oxidase located on the surface of emulsions and washed milk fat globules. Int. Dairy J. 37:117-126.

Kessler, H. G. 2002. Centrifugation-separation-cyclone separation. Pages 41-55. Food and Biology Process Engineering. Dairy Technology. Verlag A. Kessler, Munich, Germany.

Le, T. T., J. van Camp, P. A. L. Pascual, G. Meesen, N. Thienpont, K. Messens, and K. Dewettinck. 2011. Physical properties and microstructure of yoghurt enriched with milk fat globule membrane material. Int. Dairy J. 21:798-805.

Le, T. T., J. Van Camp, R. Rombaut, F. van Leeckwyck, and K. Dewettinck. 2009. Effect of washing conditions on the recovery of milk fat globule membrane proteins during the isolation of milk fat globule membrane from milk. J. Dairy Sci. 92:3592-3603.

Liu, Y., and R. Guo. 2008. pH-dependent structures and properties of casein micelles. Biophys. Chem. 136:67-73. 
Mao, X. Y., P. S. Tong, S. Gualco, and S. Vink. 2012. Effect of NaCl addition during diafiltration on the solubility, hydrophobicity, and disulfide bonds of $80 \%$ milk protein concentrate powder. J. Dairy Sci. 95:3481-3488.

Michalski, M., V. Briard, and F. Michel. 2001. Optical parameters of milk fat globules for laser light scattering measurements. Lait 81:787-796.

Michalski, M., F. Michel, D. Sainmont, and V. Briard. 2002. Apparent $\zeta$-potential as a tool to assess mechanical damages to the milk fat globule membrane. Colloids Surf. B Biointerfaces 23:23-30.

Michalski, M. C., N. Leconte, V. Briard-Bion, J. Fauquant, J. L. Maubois, and H. Goudédranche. 2006. Microfiltration of raw whole milk to select fractions with different fat globule size distributions: Process optimization and analysis. J. Dairy Sci. 89:3778-3790.

Morin, P., R. Jiménez-Flores, and Y. Pouliot. 2007. Effect of processing on the composition and microstructure of buttermilk and its milk fat globule membranes. Int. Dairy J. 17:1179-1187.

Phan, T. T. Q., M. Asaduzzaman, T. T. Le, E. Fredrick, P. Van der Meeren, and K. Dewettinck. 2013. Composition and emulsifying properties of a milk fat globule membrane enriched material. Int. Dairy J. 29:99-106.

Phan, T. T. Q., K. Moens, T. T. Le, P. Van der Meeren, and K. Dewettinck. 2014. Potential of milk fat globule membrane enriched materials to improve the whipping properties of recombined cream. Int. Dairy J. 39:16-23.

Piry, A., A. Heino, W. Kuehnl, T. Grein, S. Ripperger, and U. Kulozik. 2012. Effect of membrane length, membrane resistance, and filtration conditions on the fractionation of milk proteins by microfiltration. J. Dairy Sci. 95:1590-1602.

Rabiller-Baudry, M., G. Gesan-Guiziou, D. Roldan-Calbo, S. Beaulieu, and F. Michel. 2005. Limiting flux in skimmed milk ultrafiltration:
Impact of electrostatic repulsion due to casein micelles. Desalination 175:49-59.

Rombaut, R., V. Dejonckheere, and K. Dewettinck. 2006. Microfiltration of butter serum upon casein micelle destabilization. J. Dairy Sci. 89:1915-1925.

Sajedi, M., A. Nasirpour, J. Keramat, and S. Desobry. 2014. Effect of modified whey protein concentrate on physical properties and stability of whipped cream. Food Hydrocoll. 36:93-101.

Schramm, L. L. 2014. Colloid stability. Pages 163-204. In Emulsions, Foams, Suspensions, and Aerosols. Microscience and Applications. 2nd ed. Wiley-VCH, Somerset, DE.

Sharma, P., I. Oey, and D. W. Everett. 2015. Interfacial properties and transmission electron microscopy revealing damage to the milk fat globule system after pulsed electric field treatment. Food Hydrocoll. 47:99-107.

Singh, H. 2006. The milk fat globule membrane-A biophysical system for food applications. Curr. Opin. Colloid Interface Sci. 11:154163.

Tashvigh, A. A., A. Fouladitajar, and F. Zokaee Ashtiani. 2015. Modeling concentration polarization in crossflow microfiltration of oilin-water emulsion using shear-induced diffusion; CFD and experimental studies. Desalination 357:225-232.

Walstra, P., J. T. M. Wouters, and T. J. Geurts. 2006. Proteins. Pages 63-83 in Dairy Science and Technology. 2nd ed. Taylor \& Francis, Boca Raton, FL.

Ye, A., J. Cui, and H. Singh. 2011. Proteolysis of milk fat globule membrane proteins during in vitro gastric digestion of milk. J. Dairy Sci. 94:2762-2770.

Zou, X., Z. Guo, Q. Jin, J. Huang, L. Cheong, X. Xu, and X. Wang. 2015. Composition and microstructure of colostrum and mature bovine milk fat globule membrane. Food Chem. 185:362-370. 